\title{
A construção da queda em Solness, O Construtor, de Henrik Ibsen ${ }^{1}$
}

\author{
Vicentonio Regis do Nascimento Silva ${ }^{\mathrm{i}}$
}

\section{RESUMO}

Em Solness, o construtor, Henrik Ibsen descreve a ascensão e a queda de um arquiteto que, na tentativa de ampliar seu poder econômico, social e simbólico, perde o discernimento entre o real e o ilusório, morrendo logo depois de desequilibrar-se no topo de uma de suas construções. As personagens femininas alternam-se nas casas actanciais de oponente e adjuvante, ora lutando pela vida do empreiteiro, ora desdobrando-se para que ele morra. Este artigo pretende demonstrar as convergências, as divergências, os diálogos e os trânsitos das personagens femininas na manipulação do protagonista.

Palavras-chave: Ibsen; feminino; drama moderno.

\begin{abstract}
In Solness, the master builder, Henrik Ibsen writes about ascension and decline of an architect who wants to increase his economic, social and symbolic power, but he loses discernment between real and illusion. He dies after falling from one of his buildings. The female characters alternate in the opponent and adjuvant actuarial squares, sometimes fighting for the life of the contractor, sometimes striving for him to die. This article intends to show how female characters manipulate protagonist.
\end{abstract}

Keywords: Ibsen; female; modern drama.

\footnotetext{
i Doutor em Letras/Literatura pela Universidade Estadual de Londrina (UEL), instituição na qual defendeu a tese sobre as representações do feminino na obra do dramaturgo norueguês Henrik Ibsen. E-mail: vicrenos@yahoo.com.br
} 
SENHORA SOLNESS (assustada, diz a meia voz, para HILDA) - Pelo amor de Deus! Ali vem ele! Trate de lhe tirar essa loucura da cabeça. Sejamos amigas, senhorita Wangel. É possível, não é?

HILDA (atirando-se violentamente ao pescoço da SENHORA SOLNESS) Oh! Sim, é possível. (IBSEN, 1960b, p. 547)

Se as mulheres atravessam sua obra, tomando mais importância e causando maior repercussão a partir de Casa de bonecas, as personagens masculinas de Ibsen entram em um ciclo de redimensionamento, desestabilizando a imagem de homem (viril, corajoso) diante dos preceitos do presente abalados por atos do passado. Assim, Solness, o construtor e John Gabriel Borkman integram a quarta fase de suas peças:

\begin{abstract}
Ibsen desiste de propor a verdade e a liberdade aos homens. Elas continuam a ser os grandes valores do autor, mas ele admite que a mentira pode ser vital para os seres mais frágeis e a liberdade pode assustar a muitos. Sua forma dramática passa a valorizar a estrutura mais aberta das frases e a ambiguidade ou inconclusão das palavras. Avançando cada vez mais pelo mundo interior, ele passa a perscrutar como os indivíduos negam ou desistem de seus desejos, ou os transformam em sonhos. (MENEZES, 2006, p. 57)
\end{abstract}

A pesquisadora agrupa os títulos que se dedicam a esmiuçar psicológica, moral ou teologicamente o espírito das personagens. Notam-se algumas diferenças relativas a, por exemplo, Um inimigo do povo ou Casa de bonecas, nos quais as personagens femininas - assim como as masculinas - transcorrem boa parte da ação em busca de alcançar seu objeto-valor enquanto, em A dama do mar ou mesmo neste Solness, as personagens tentam se libertar de prescrições fixadas no passado que, no presente/futuro, encontram dificuldades de acomodação.

O drama, dividido em três atos, concentra-se nos conflitos internos de sua personagem principal: o arquiteto Halvard Solness. Aqui, exige-se a aplicação da técnica analítica com a finalidade de compreender o desencadeamento dos fatos pretéritos. O retorno de Ibsen ao seu país e o fim de sua vida coincidem com uma espécie de reflexão que acompanha as personagens masculinas levando alguns de seus estudiosos a identificar na arquitetura dramatúrgica características particulares do autor, de sua esposa e de sua mãe (MATA, 1973).

O primeiro ato - transcorre no gabinete de trabalho do arquiteto, acoplado a sua casa - apresenta o chefe e seus empregados. Solness comanda um pequeno grupo composto por Knut Brovik, seu filho Ragnar Brovik e Kaia Fosli. 
Instala-se o entrevero pelo choque entre a maturidade/velhice de Solness e a juventude de Ragnar Brovik, Kaia Fosli e, mais adiante, Hilda Wangel. A juventude e a ascensão - e, inversamente, a derrocada - de novos nomes nos negócios e no âmbito profissional esbarram nas querelas internas de Solness. Ragnar, funcionário do arquiteto, tem se destacado com seu trabalho, quase sempre ignorado pelo chefe. $\mathrm{O}$ objeto-valor de Ragnar: ascensão profissional. Para impedir que o sujeito alcance seu objeto-valor, Solness, ocupando a casa actancial de oponente, conta com o apoio de Kaia. Além de empregada, é prima e noiva de Ragnar e sobrinha de Knut Brovik.

Quando se pensa nas personagens, imediatamente se aplicam critérios de distinção de seu ethos de maneira a se observar, por exemplo, quem seria a personagem vulnerável a se render aos apelos ou trejeitos da personagem influenciadora. A esse procedimento - de se entregar ou de forçar o outro a ceder - se dá o nome de manipulação. Entretanto,

\begin{abstract}
A manipulação só será bem-sucedida quando o sistema de valores em que ela está assentada for compartilhado pelo manipulador e pelo manipulado, quando houver uma certa cumplicidade entre eles. [...]

Não se deixar manipular é recusar-se a participar do jogo do destinador, pela proposição de um outro sistema de valores. Só com valores diferentes o sujeito se safa da manipulação. (BARROS, 2011, p. 33)
\end{abstract}

A relação manipulador/manipulado (superior/subalterno) concretiza-se no momento em que a competência do manipulador altera a do manipulado.

A rubrica do primeiro ato descreve os três funcionários que, trabalhando no escritório sem a presença do arquiteto, falam a respeito de problema entre eles e o chefe. O problema do pai relaciona-se à saúde, à falta de disposição física e à ausência de oportunidades de o filho galgar os degraus dentro da empresa. O imbróglio do filho resume-se ao último do pai. Nesse meio-termo, Kaia tenta a todo custo impedir que os dois se rebelem. Embora não se delineie a insatisfação de pai e filho, já são sugeridos os impedimentos para alcançarem seu objeto-valor. O impedimento de acesso ao objetovalor terá, na condição de oponentes, não apenas Solness, mas também Kaia:

BROVIK - Sinto que vou piorando dia a dia.

RAGNAR (levanta-se e aproxima-se do pai) - Era melhor que fosses para casa, papai, e procurasses dormir.

BROVIK (irritado) - Ir para a cama, não? Queres que eu morra, então?

KAIA - Pois então vê se dás um passeio curto. 
RAGNAR - É isso. Eu te acompanharei.

BROVIK (vivamente) - Não sairei antes dele chegar. Tenho de explicar-me hoje mesmo... (Com cólera surda.) Com ele... com o patrão!

KAIA (ansiosamente) - Não, tio! Espera ainda, eu te peço!

RAGNAR - É mesmo, pai: será melhor que esperes.

BROVIK (respirando com dificuldade) - Esperar, hein? Mas é que não tenho tempo para esperar. (IBSEN, 1960b, p. 492)

As rubricas ajudam a construir o processo enunciativo. Observa-se o destoar dos desejos de Brovik e Kaia: o primeiro anseia "vivamente", "irritado", com "cólera surda" e "respirando com dificuldade" enfrentar o patrão com o objetivo de esclarecer e solucionar sua rusga enquanto a segunda tenta "ansiosamente" impedir a iniciativa do tio.

A rubrica do início do primeiro ato descreve Kaia como moça de mais ou menos vinte anos, delgada, “[...] vestida cuidadosamente, mas de aparência doentia" (IBSEN, 1960b, p. 492). A insistência "ansiosa" de impedir o atrito do tio com o arquiteto até então não vem explicada, mas, após o diálogo acima transcrito, Solness aparece no escritório e, a meia-voz, pergunta se pai e filho já se foram. Também com voz abafada e evitando exposição, ela responde negativamente. Entrando no ambiente, afasta-se da intimidade com que a tratava aos cochichos e assume um tom eminentemente formal:

SOLNESS (em voz alta) - Que está escrevendo aí, senhora Fosli?

KAIA (estremecendo) - Oh! Simplesmente...

SOLNESS - Vamos ver, senhorita. (Curva-se para ela, finge que olha no livro grande e murmura:) - Kaia!...

KAIA (em voz baixa continuando a escrever) - Que é?

SOLNESS - Por que motivo tira a sua viseira sempre que eu chego?

KAIA (sem mudar de tom) - Porque ela me deixa feia.

SOLNESS - E você não quer parecer feia, não é, Kaia?

KAIA (virando a meio a cabeça para ele) - Por nada deste mundo. Pelo menos a seus olhos.

SOLNESS (passando levemente a mão pelos cabelos de Kaia) - Pobre, pobre Kaiazinha...

KAIA (baixando a cabeça) - Podem ouvi-lo. (IBSEN, 1960b, p. 493)

Os sussurros entre patrão e empregada denotam um relacionamento diferenciado. Solness a "usa": sua meta não é usufruir de seus dotes sexuais, mas de sua influência sobre o tio e o primo que não cedem à manipulação.

Quando Brovic acrescenta, ao fim de sua fala, que precisa conversar com ele, o patrão, imediatamente se instala o marco actancial em que um "eu" é diferente de um "tu", criando-se um distanciamento entre os dois. Esse distanciamento impede a 
desistência de pai e filho de seu objeto-valor pelo fato de o sistema de valores do empregador - ele, o patrão! - não ser igual ou semelhante ao dos empregados.

Nem os diálogos, nem as rubricas indicam se Solness tinha perfil de homem bonito, sedutor ou atraente, mas é fato que manipula sua empregada por meio de seu discurso íntimo e galanteador. Assim, direciona Kaia por, pelo menos, duas espécies de manipulação: a manipulação por sedução e a manipulação por tentação.

Na primeira, Solness detém uma imagem positiva de Kaia e, sabendo de sua vulnerabilidade a respeito do quesito beleza, aproxima-se habilmente para alcançar seu objeto-valor. Kaia já adentrou o sistema de valores de Solness e torna-se seu objeto modal (o veículo que ajudará a concretizar a pretensão do sujeito dramatúrgico). Essa confissão de querer-fazer algo que o ajude é informada pela personagem quando, ainda nos primeiros diálogos, conta ao patrão que, em nenhuma hipótese, pretende ficar feia aos seus olhos. Cria-se um contrato fiduciário em que, pelo menos neste primeiro momento, uma parte compromete-se a seduzir (Solness) e outra parte aceita a sedução (Kaia). A funcionária então assume a vontade de querer-fazer algo, determinando-se objeto-modal.

Mas não é apenas pela sedução que Solness direciona Kaia. Também a manipula pela tentação, pois detém os valores positivos (criados por ela a partir da aproximação dele) de transformá-la em seu objeto-modal. No caso de Kaia, o "eu" (Kaia) e o "tu" (Solness) não criam um distanciamento, esfriamento ou estranhamento, mas aproximação, intimidade e familiaridade. Forja-se um sistema de cooptação e cooperação. Kaia ocupa tanto a casa de oponente ao objeto-valor de Ragnar quanto a de adjuvante ao objeto-valor de Solness, respectivamente consistentes em permitir e impedir a ascensão profissional do jovem desenhista.

Kaia percebe distorcidamente seu vínculo com Solness: pouco assimila dos indícios e pistas do discurso do patrão sobre a relação meramente contratual entre ambos. Por mais que ensaie aproximação sedutora e atraente, que não será descoberta pelas demais personagens, apenas eventualmente deduzida pela esposa, o arquiteto desenvolve relação hierárquica em que se destacam o poder da ordem e o exercício da obediência.

As exclamações nos diálogos e as rubricas indicam o jogo de poder em que a persuasão masculina desdobra-se na dominação burocrática do patrão - um sedutor 
sempre lançaria mão da versão carismática para encantar sua vítima ou para entrar em conjunção com o pathos de seu enunciatário:

SOLNESS (severamente) - E trate de resolver aquele outro assunto, ouviu? KAIA - Oh! Se isso dependesse de mim, eu...

SOLNESS - Quero que o assunto fique resolvido, já lhe disse! Amanhã, sem mais tardar!

KAIA (ansiosamente) - Se não houver outro meio, consinto em romper com ele.

SOLNESS (saltando) - Romper! Ora essa! Está louca? Quer romper? (IBSEN, 1960b, p. 499)

A oposição semântica juventude versus maturidade manifesta-se de formas diferentes. Se, no caso de Kaia, parece estar em conjunção aos interesses de Solness, é fator de disjunção ao objeto-valor quando pensamos em Ragnar. No diálogo travado entre Brovik e Solness, aclara-se a intenção de Solness manter o filho de seu empregado - de quem, no passado, também fora empregado - na subalternidade por tempo indefinido.

Quando Solness entra no escritório, Ragnar e Brovik relatam a visita de casal, interessado na construção de casa de campo, a quem o arquiteto denomina "estranhos", desmerecendo eventual prestação de serviço: "Procurem quem quiserem. Pouco se me dá” (IBSEN, 1960b, p. 494). Em seguida, Brovik pleiteia a oportunidade de o filho assinar projetos ou do apoio profissional para que monte seu próprio negócio. O diálogo seguinte comprova o capricho de Solness ao criar empecilhos para a autonomia do empregado jovem, cujos passos iniciais repetem, menos violentamente, o percurso adotado pelo patrão que, para sair da anterior condição de empregado e assumir a de chefe, destronara outros construtores.

SOLNESS (aborrecido) - Mas que inferno! Eu, afinal, não posso fazer com que lhe venham encomendas da lua! BROVIK - Justamente agora, ele poderia ter uma bela encomenda, um grande trabalho.

SOLNESS (estremecendo) - Ele?

BROVIK - Sim, se o senhor consentir.

SOLNESS - Que trabalho é esse?

BROVIK - Ele poderia construir essa casa de campo em Loevstrand.

SOLNESS - Essa casa de campo? Mas se sou eu que a vou construir!... BROVIK - O senhor não faz questão disso.

SOLNESS (saltando) - Não faço questão? Eu? Quem se atreve a supô-lo? BROVIK - O senhor mesmo acaba de dizê-lo.

SOLNESS - Ora! Não leve em conta tudo o que eu digo, assim. Acha que Ragnar poderia construir essa casa de campo? (IBSEN, 1960b, p. 495) 
A aparente oposição moderação versus ímpeto, ramificação da anterior juventude versus maturidade, na prática, esconde o jogo entre autoritarismo versus autoridade. Diferentemente do fascínio sobre Kaia, o construtor distancia-se de práticas cooperativas, acirrando a disputa com seus funcionários.

O diálogo prossegue com a sugestão de o patrão transferir a responsabilidade da empreitada a Ragnar: "SOLNESS - Eu? Ceder o lugar a seu filho?" (IBSEN, 1960b, p. 496). O empregado alega o grande número de obras. Por que concentrar todos os trabalhos em suas mãos? "SOLNESS - Não há tanto assim [trabalho]. Mas a questão não é essa. Fique sabendo que eu jamais recuarei, jamais, diante de quem quer que seja, por minha vontade! Nunca, repito-lhe" (IBSEN, 1960b, p. 496).

Destemor? Talvez teimosia que o acompanhará e o impelirá a cobrar de Kaia, diante do amor que ela afirma sentir por ele, a conduta de convencer Ragnar a desistir da proposta de montar seu próprio negócio, reforçando-se quem manipula/domina/subjuga e quem é manipulado/dominado/subjugado:

KAIA (torcendo as mãos) - Mas não me poderei separar do senhor! Isso me parece de todo, de todo impossível!

SOLNESS - Nesse caso trate de tirar da cabeça de Ragnar esse capricho tolo. Case-se com ele quantas vezes quiser... (Corrigindo-se.) Quero dizer... Convença-o de conservar-se no bom emprego que tem aqui em casa. Nesse caso, querida Kaia, eu poderei conservá-la... a você também. (IBSEN, 1960b, p. 498)

A responsabilidade de destruir os sonhos de Ragnar fica a cargo de Kaia. Solness aproveita-se da paixão para manipulá-la e alterar sua competência de destinatária de seu discurso, estimulando-a a querer-fazer o designado por ele. Informado ainda no primeiro ato, o leitor/espectador toma conhecimento do incêndio que destruiu a casa dos sogros e de algum segredo, revelado a seguir, da morte dos filhos gêmeos do arquiteto.

Ainda no primeiro ato, Hilda Wangel entra no escritório do construtor, mudando seu rumo profissional e pessoal. Ao tratar do encontro inicial entre Hilda e Solness, Iná Costa salienta que

Hilda se lembra de coisas que aconteceram, como a inauguração, em que ficou fascinada com a figura do construtor no alto da torre, depositando uma 
coroa de flores, como era o costume. Mas também se "lembra" do que não aconteceu, como o beijo que teria recebido de Solness e sua promessa de fazer uma torre para ela. Solness deixa a ilusão prosperar, concluindo que a moça lhe dava a energia de que precisava para enfrentar a mocidade [...]. (COSTA, 2011, p. 18)

Da mesma maneira que Solness manipula Kaia com o objetivo de impedir o desligamento de Ragnar do escritório, Hilda inverte a manipulação e a aplica contra Solness por meio da confusão entre o que efetivamente aconteceu e o que ilusoriamente teria ocorrido. Fatos incontroversos: Solness esteve na cidade de Hilda, construiu a igreja, subiu até a torre com a finalidade de depositar tradicional coroa de flores, presenciou a multidão ovacionando seu feito, comemorou com os habitantes da localidade. Fatos obscurecidos: promessas. Entre estas, duas se sobressaem. A primeira delas, a construção metafórica da proposta de relacionamento:

\footnotetext{
HILDA - O senhor disse que me achava encantadora com o meu vestido branco e que eu parecia uma princesinha.

SOLNESS - Isso deve ser verdade, senhorita Wangel. E, além disso, nessa noite, eu me sentia tão alegre, tão livre...

HILDA - E o senhor disse mais: que, quando eu fosse grande, eu seria a sua princesa.

SOLNESS (esboçando um sorriso) - Como? Como? Eu também disse isso? HILDA - Sim, o senhor disse. E, quando eu lhe perguntei quanto tempo teria de esperar, o senhor me respondeu que dentro de dez anos, voltaria, como um troll, para me raptar, e me levar para a Espanha, ou não sei aonde. E que uma vez que chegássemos lá o senhor me compraria um reino.

SOLNESS (com o mesmo sorriso de antes) - Sim, depois de uma boa refeição, fica-se muito generoso. Mas então é certo que eu disse tudo isso? (IBSEN, 1960b, p. 511-512)
}

Hilda seduz Solness. Apesar da falta de convicção da conversa após o jantar, o construtor, senão rechaça tal hipótese, concede a si - e também a ela - o benefício da dúvida, estimulando o prolongamento da aventura romântica com a filha do médico de vilarejo. Esses sorrisos esboçados nas rubricas expressam mais espanto do que anuência: intensificam-se as possíveis violências igualmente esquecidas - nunca existidas? - por ele, mas detalhadas por ela.

SOLNESS - Que teria eu feito, Santo Deus?

HILDA - Não faltava mais nada que o senhor o tivesse esquecido! De uma coisa dessas a gente sempre se lembra, quer-me parecer.

SOLNESS - Sim, sim, ponha-me um pouco na pista e é provável que... Vamos ver.

HILDA (olhando-o fixamente) - O senhor me tomou em seus braços e me beijou, Senhor Solness! 
SOLNESS (abrindo a boca e levantando-se) - Como! Eu fiz isso? HILDA - Sim, o senhor fez isso! O senhor me pegou nos seus dois braços, me inclinou para trás e me beijou não sei quantas vezes. (IBSEN, 1960b, p. 512)

Solness duvida das afirmações de Hilda. Refuta quaisquer que sejam as chances de convidá-la a fugir para outro país e, principalmente, de beijá-la, de dominá-la. Eis o momento em que, aproveitando-se de sua situação frágil diante do homem forte, Hilda o desestabiliza: "SOLNESS (sorrindo) - Como pude esquecer-me de uma coisa dessas!" (IBSEN, 1960b, p. 513).

Interessante frisar: o mesmo artifício de convencimento amoroso de Solness contra Kaia - lembrando que o carisma é substituído algumas vezes pela dominação burocrática - é utilizado por Hilda contra o arquiteto, mas, neste caso específico, considerando as promessas à menina adolescente, que depois de dez anos vem em busca de seu prometido - ao entrar na casa dele, a primeira afirmação de Hilda é "vejo que o senhor não me está reconhecendo" (IBSEN, 1960b, p. 506) - a personagem feminina aplica a manipulação por provocação.

Detendo o saber, Hilda cria uma imagem negativa do manipulado (Solness fezlhe promessas - um reino equivaleria a um casamento? - e a tomou à força) e, com isso, instala nele a competência do dever-fazer, configurada pela obrigação não-cumprida de desposá-la.

Reforça-se o sentimento de culpa de Solness pelo espaço em que transcorreram promessas, abraços e beijos. Enquanto todos comemoravam na casa do pai, provavelmente no pavilhão onde passava boa parte do tempo a dama do mar, Hilda estava "sozinha" numa "sala" (IBSEN, 1960b, p. 511) quando Solness listou promessas e se arremessou sobre ela. O sentimento de culpa torna-se ao mesmo tempo preocupação e alívio de modo que, no fim do primeiro ato, encontramos um Solness fascinado pelo amor de Hilda: "Você é tudo quanto me estava faltando" (IBSEN, 1960b, p. 518).

Ainda neste primeiro ato vislumbra-se a desenvoltura de Aline, esposa do arquiteto, na conservação de seu casamento. Aline tem conhecimento da relevância da mulher casada na sociedade em que vive de maneira que, embora tenha indícios das relações extraconjugais, concretizadas dentro de sua casa, ela as absorve sem, contudo, perder a oportunidade de denunciá-las ironicamente. Uma relação marital equilibrada na 
crença do marido na infantilização da esposa e nas sequelas masoquistas internalizadas pelo casal.

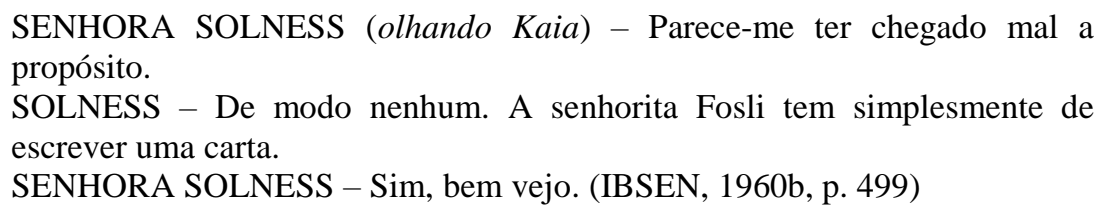

A ironia delicada assevera a liberdade masculina, complacentemente subscrita pela esposa: a faculdade de agir sexualmente dele transforma-se na obrigação indiscutível dela; a escolha dele é a única alternativa dela transmutada na dubiedade da linguagem de Ibsen.

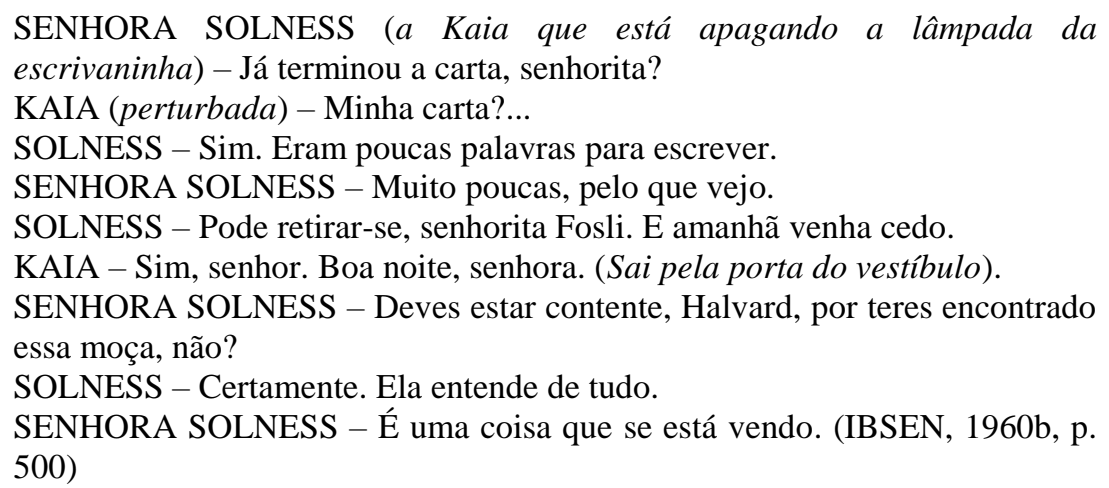

A "coisa que se está vendo" forja-se no silêncio, na interdição e no esquecimento especialmente articulados, conforme ressaltamos no parágrafo anterior, pela quebra do código fechado já que o marido transmuta a conotação do discurso da esposa em denotação, articulando propositalmente ruído na comunicação. Os enunciados de Aline e Solness não nos permitem a inferência de liberdade sexual, pactuada horizontalmente entre marido e mulher.

O segundo ato concentra a rememoração de Solness. Suas confissões fluem. Entre elas, a de que permitiu inadequação na casa dos sogros, responsável pelo incêndio que a destruiu, contaminou o leite da esposa e matou os filhos gêmeos; o enriquecimento por loteamento de terrenos e da construção de vilas; a destruição de Brovik e a duplicação de esforços para impedir a subida de Ragnar. 
A confirmação da influência de Hilda sobre Solness acontece no fim do segundo ato: o arquiteto demite Kaia e a substitui com o assentimento da esposa. Também demite o tio e o primo/noivo dela (IBSEN, 1960b, p. 541-542).

A esposa conhece o marido. Já sabia de seu possível envolvimento com a empregada e pressupõe a mudança de foco com a chegada de Hilda. Aline é uma mulher destroçada - morte dos filhos, incêndio e repartição do terreno de sua casa original, construção de uma nova moradia sobre os escombros da antiga, desaparecimento de suas lembranças marcadas nos álbuns de fotografia ou nas nove bonecas consumidas pelas labaredas. São poucas as suas falas. Quando se direciona ao marido, dificilmente o contesta ou o confronta. Assimila, absorve, internaliza, se decompõe. Afinal, ele teria alguma "reserva" não apenas para as funções burocráticas do escritório, mas principalmente para os desempenhos prazerosos da cama, reavivados por uma jovem adolescente? - com muito menos idade, muito menos problemas e muito menos impedimentos.

O sentimento de culpa, o vazio pela falta de cumprimento de suas obrigações como mãe e esposa a atormentam a, assim como o marido, reconhecer que a vida se constitui numa casa que jamais se tornará um lar (IBSEN, 1960b, p. 522). Um lar precisa de uma mãe que cuide dos filhos e do marido. A função materna desperta a curiosidade de Hilda (IBSEN, 1960b, p. 527-529). Segundo Aline, a vida se arrefece diante dos valores que damos às pequenas perdas e, em suas dores, a perda dos filhos, comparada à das bonecas e das lembranças, parecia insignificante:

HILDA - As bonecas?...

SENHORA SOLNESS (com lágrimas na voz) - Eu tinha nove bonecas encantadoras.

HILDA - E todas se queimaram?

SENHORA SOLNESS - Todas! Oh! Isso me causou tanto pesar, tanto!

HILDA - Sim? A senhora tinha conservado todas essas bonecas? Desde a infância?

SENHORA SOLNESS - Não as conservei. As bonecas e eu continuamos a viver juntas.

HILDA - Mesmo depois que a senhora ficou grande? (IBSEN, 1960b, p. 546-547)

Mesmo depois de adulta, a relação entre Solness e Aline persiste na infantilização da mulher - simbolizada pelas bonecas das quais sentiu mais saudades do que dos filhos e com quem provavelmente conversava para minimizar os efeitos da 
solidão - e no masoquismo - aceitando as prováveis aventuras do marido com Kaia e Hilda.

O sentimento de culpa que consome Aline atormenta a mulher contemporânea que, em grande parte das situações, estagna seu percurso diante das dificuldades. Contudo, seja para a personagem criada nas últimas décadas do século XIX, seja para a mulher real contemporânea, o primeiro passo para se livrar desse sentimento de culpa é romper as mais diferentes espécies de apropriações.

\begin{abstract}
A importância da apropriação de si está, portanto, na percepção da mulher como sujeito de sua própria vida, o que necessariamente associa-se à superação da ideologia de naturalização do sexo. Afinal, como pensar em uma consciência coletiva voltada para a transformação social se individualmente uma mulher encontra-se alienada de si, sem autonomia sobre sua vida e restringida a cuidar dos outros em detrimento de si? Esse processo de apropriar-se de si está radicalmente articulado com o descobrir-se feminista (CISNE, 2014, p. 176-177).
\end{abstract}

O terceiro ato encerra a ação: nele, impulsionado por Hilda, advertido pela esposa, assistido pela multidão, Solness tenta superar suas vertigens e sobe à torre com o objetivo de depositar flores nela. Antes da fatalidade, Hilda e Aline conversam sobre o jardim e a nova morada. Nesse momento, a confissão de Senhora Solness demonstra sua subserviência ao marido, motivo pelo qual jamais o confrontou ao tratar de Kaia nem protestou quando percebeu as articulações de Hilda: “[...] É um dever, para mim, fazer a vontade dele. Mas obedecer, não é sempre muito fácil” (IBSEN, 1960b, p. 545). Hilda sabe dos sofrimentos pelos quais passou. Indagada de como recebeu tais informações, responde que Solness as transmitiu: "SENHORA SOLNESS - É tão raro ele abrir-se comigo..." (IBSEN, 1960b, p. 546).

Aline age, na condição de oponente ao objeto-valor de Hilda, na intenção de impedir o desatino do marido: "SENHORA SOLNESS (assustada, diz a meia voz, para Hilda) - Pelo amor de Deus! Ali vem ele! Trate de lhe tirar essa loucura da cabeça. Sejamos amigas, senhorita Wangel. É possível, não é?” (IBSEN, 1960b, p. 547). Hilda continua a perseguir seu objeto-valor: Solness. Para alcançar tal objetivo, atiça-o a romper o casamento (IBSEN, 1960b, p. 550).

Hilda o estimula a readquirir sua juventude, simbolizada pela quebra de limites e pela superação física. Sabe inequivocamente de suas restrições advindas da idade e do medo: 
RAGNAR - Sim, é como lhe digo. Esse grande construtor... que não se arreceia de destruir a felicidade dos outros, de agir como ele o fez com meu pai e para comigo... tem medo de subir a um simples andaime. Oh! Quanto a isso ele nunca se animará (IBSEN, 1960b, p. 554).

Alertada pela esposa e, agora, pelo empregado, tem informações suficientes para deduzir a alta probabilidade de subida/descida fatal do construtor. Quando toma conhecimento do desaparecimento da coroa de flores, Aline se desespera e, mesmo diante da inimizade entre o marido e seus ex-funcionários, suplica que ambos - pai e filho - saiam em busca do arquiteto. Neste instante, Aline, Brovik e Ragnar ocupam concomitantemente a casa actancial de oponentes ao objeto-valor de Hilda: a subida de Solness. Além de sujeito dramatúrgico, Hilda também ocupa a casa actancial de adjuvante, impulsionando Solness à morte:

\footnotetext{
HILDA - Acreditei no senhor durante dez anos!

SOLNESS - Precisa acreditar sempre.

HILDA - Acreditarei, se o vir escalar a torre, sem receio, até o cimo.

SOLNESS (com um suspiro penoso) - Não, Hilda, essas coisas não se repetem todos os dias.

HILDA (com paixão) - Mas eu quero! Eu quero! (Com voz suplicante.) Ainda uma vez, uma só! Sim? Faça ainda o impossível. (IBSEN, 1960b, p. 558)
}

Se Solness não conseguiu alcançar seu objeto-valor (impedir a independência profissional de Ragnar com a ajuda de Kaia), habilmente Hilda o atinge: Solness sobe à torre com a coroa. As oposições semânticas (masculino versus feminino, velhice/maturidade versus juventude, desilusão versus sonho, resignação versus alegria, moderação versus ímpeto, autoritarismo versus autoridade, autonomia versus submissão e liberdade versus prisão) redesenham-se: Solness é tomado por uma juventude artificial em que sonho, alegria, ímpeto, submissão e prisão enquadram-se patologicamente no seu senso de direção, de consciência de si, de suspensão da realidade:

\footnotetext{
A imagem da queda expressa uma possibilidade concreta da espacialidade vivida, do corpo habitando o espaço: ela é uma estrutura antropológica do mundo, uma forma de habitá-lo, aquela da perda do apoio e da harmonia, da ruptura em uma corporeidade tranquila. Mas além do corpo que cai realmente, a imagem da queda traduz a essência mesma da perda do escoramento e do vivido de terror que lhe é consubstancial. A queda descreve uma possibilidade fundamental de ser no mundo: a perda do equilíbrio, o colapso, o terror. (CHAMON, 2011, p. 5)
} 
A perda de equilíbrio, o colapso e o terror inoculam-se não apenas em Solness, mas também em sua esposa e, principalmente, em Hilda. Solness desequilibra-se, cai da torre, a multidão precipita-se sobre o jardim, a esposa desmaia. Observando sua conquista patológica e dramatúrgica, Hilda encerra o drama: "HILDA (imóvel, com uma expressão de desvario e de triunfo) - Mas atingiu o cimo! E eu ouvi no ar sons de harpa. (Agitando o xale e clamando com paixão concentrada e selvagem.) Meu mestre!... meu mestre!" (IBSEN, 1960b, p. 562).

\section{Referências}

BARROS, Diana Luz Pessoa de. Teoria semiótica do texto. São Paulo: Ática, 2011.

CHAMON, Jeanine. "Fenomenologia e psicopatologia do espaço vivido segundo Ludwing Binswanger: uma introdução”. In: Revista da abordagem gestáltica, vol. XVII (1), p. 3-7, jan.-jun., 2011.

CISNE, Mirla. Feminismo e consciência de classe no Brasil. São Paulo: Cortez, 2014.

COSTA, Iná Camargo. “Transições”. In: Literatura e Sociedade, n.15, São Paulo, p. 1441, 2011.

IBSEN, Henrik. “A dama do mar". In: . Seis dramas. Porto Alegre: Globo, 1960, p. 395-473. $\overline{207-300 .}$

. "O pato selvagem". In: . Seis dramas. Porto Alegre: Globo, 1960a, p.

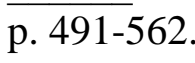

. "Solness, o construtor". In: Seis dramas. Porto Alegre: Globo, 1960b, . Um inimigo do povo. Porto Alegre: L\&PM, 2002. $\overline{1675-1751 .}$ "Hedda Gabler". In: . Teatro completo. Madrid: Aguillar, 1973, p. . "Hedda Gabler". In: . Théâtre. Paris: Gallimard, 2006, p. 1337-1421. $\overline{1569-1644 .}$ "John Gabriel Borkman". In: . Théâtre. Paris: Gallimard, 2006a, p. . Casa de bonecas. Mairiporã: Veredas, 2012. 
MATA, German Gomez de la. "Henrik Ibsen". In: IBSEN, Henrik. Teatro completo. Madrid: Aguilar, 1973, p. 9-140.

MENEZES, Tereza. Ibsen e o novo sujeito da modernidade. São Paulo: Perspectiva, 2006.

Recebido em: 08/06/2020

Aceito em: 23/06/2020

\footnotetext{
${ }^{1}$ Este artigo é versão adaptada de um dos capítulos da tese "Entre sujeito e objeto: representações femininas em Ibsen”, defendida, em 2017, no Programa de Pós-Graduação em Letras da Universidade Estadual de Londrina, sob a orientação da Prof. ${ }^{a}$ Dr. ${ }^{a}$ Sonia Pascolati.
} 